particular culture is the more conspicuous are the acid-fast forms.

In the case of St. leprae it would appear that the conditions of parasitic life specially favour the acquirement of acid-fast properties; under saprophytic conditions of growth the rod segments tend to remain non-acid-fast. With Koch's parasite of tuberculosis acid-fast properties are acquired quickly during saprophytic growth; it is only in very young cultures that the non-acid-fast forms described by Klein and others can be demonstrated.

What evidence is available on the point suggests that the acid-fast forms of Streptothrix may represent not only persistent but also specially resistant elements. The spherical spores of the strepiotricheae are generally distinctly less resistant against injurious physical and chemical influences than are the spores of fission fungi; and it may be that a second resistant element-the acidfast rod form-has come into existence. Thus, Marino ${ }^{7}$ found that the acid-fast forms of the parasite of tuberculosis preserved their vitality for a considerable time in the intestinal canal of the leech, resisting the action of the digestive juices for as long as fifteen months. At the end of that time there was marked attenuation of virulence; but still inoculation of the parasites into the guinea-pig was followed in some cases by a very slow infection which resulted in death. There is also evidence of a probably similar kind with regard to the parasite of leprosy. It has been suggested that growth of this organism on artificial media is favoured in symbiosis with intestinal amoebae, and Beauchamp Williams ${ }^{10}$ has recorded his own experiments bearing on this question. With certain strains of his streptothrix the acid-fast forms appeared to die out in the course of successive subcultures. Then subcultures which appeared to consist of non-acid-fast diphtheroid rod segments were mixed with amoebae. At the end of forty-eight hours the amoebae were found to be full of acid-fast rod seyments. But an explanation other than that which supposes favourable symbiotic influences may be suggested. There is evidence that bacteria form a part of the natural food of the intestinal amoebae, and of Amoeba dysenteriae in particular. And under the circumstances it would seem most likely that the amoebae digest and assimilate the non-acid-fast segments of the streptothrix, and that in the struggle for prolonged existence other, more resistant, acid-fast forms survive, as Marino's experiments have shown to be the case with the acid-fast form of the parasite of tuberculosis which is resistant against the digestive ferments of the leech.

REFERENCES.
$1 \mathrm{H}$. Bayon, Demonstration of Specimens Relating to the Culture of the Leprosy Bacillus, BRITIsH MEDICAL JouRnaL, November 11 th. 1911, p. 1269. '2 Calvin, Frothingham. and Paige: Sporothrix and Epizootic Lymphangitis, Journ. of Med. Research., 1910, vol. xxiid,
p. 137. 3 A. G. R. Foulerton. On the Morphology and Pathogenic Action of Sporothrix schenckii, Trans. of the Path. Soc. of London, 1901, vol. lii, p. 259. ${ }^{4}$ A. G. R. Foulerton, The Streptotrichoses and cutaneous Abscesses caused by Sporothrix schenckii, a New Pathogenic Fungus, Journ. of Exper. Med., 1900, vol. v, p. 77. $6 \mathrm{~W}$. J. Kedrowsky, Zeitschr. f. Hygiene und Infektionslirank., 1910, vol. 1xvi, p. 1. 7 F. Marino, Compt. rend. de la Soc. de Biologie, 1911, vol. lxxi, p. $220 .{ }^{8}$ E. Pinoy, Forme de Sporotrichum beurmannii dans les lésions humaines. Sa fructification à l'intérior des capillaires, Compt. rend. de l'Acad. des Sciences, 1911, vol. clii, p. 286. 9 Beauchamp Williams, Leprosy, Supplement to the Indian Med. Gaz., May 1911. 10 Beauchamp December A Lecture on Leprosy, BRITIsH MEDICAL JodRNAL, Acid-fast Bacilli, Centralbl. $f$. Bakt., Abt. I, Orig., 1911, vol. 1xi,
p. 37 .

AT a recent meeting of the Society of Tropical Medicine and Hygiene Dr. Stannus read a paper on pellagra in Nyasaland, in which he brought forward strong evidence of the existence of the disease in that region; and Dr. Sandwith described the work donc in different States of America on the same disease. In a discussion that followed Drs. Sambon and Chalmers related the observations, already described in the JournaL (December 16th, 1911 , p. 1613), made during the tour in pellagra-infected parts of Italy, Roumania, Hungary, the Tyrol, France, and Spain. Dr. Sambon believes that flies (Simulium) play a part in the spread of the disease, and the epidemiological features encountered during the tour just mentioned lead Dr. Chalmers to take the same view. The trend of opinion seems to be to some such idea, but an enormous amount of work must still be done to prove this. Already, however, it seems proved that maize is not the operative cause of the disease, and this of itself constitutes a very important step forwards in the etiology of pellagra.

\section{A CASE OF ACTINOMYCOSIS OF THE LUNG.}

\section{By FRANK NICHOLSON, M.D.LOND.,}

gENIOR PHYSICIAN, HULL ROYAL INFIRMARY.

A young farm labourer from Holderness, aged 19, was: admitted into the Hull Infirmary under my care on September 22nd, 1911, and died on September 30th. He gave an indefinite history, but for a year he had apparently had a cough and expectoration with night sweats and dyspnoea, the sputum being generally thick, yellow, and offensive. In April last he had had pleurisy, he said.

The family history was unimportant. Both parents are living and well, and he had four sisters and three brothers who are all well but not very robust. His own previous history was one of good health, and he had lived in the country doing farm work since he left school.

Before admission he had had little medical treatment, but for the preceding fortnight he had been under the care of $\mathrm{Dr}$. Simpson of Skirlaugh, who kindly wrote to me. During this fortnight Dr. Simpson tells me the temperature was at first $102^{\circ}$, with poin in the $102^{\circ}$, wh pain in the knees and ankles, but subsequently did not night and morning and a considerable quantity of offensive night and mor

On admission into hospital on September 22nd the cough was very troublesome and the sputum very profuse, fetid, an purulent. Temperature, $102^{\circ}$; pulse, 102 ; respirations, 28. At th right base posteriorly there was dullness up to the angle of the scapula, with diminished fremitus, feeble breath sounds, a few. râles, and vocal resonance altered but little. The physical signs at the apex and in front, as also those over the left lung, back and front, were natural. The urine had a specific gravity of 1030, and contained no albumen, sugar, or other abnormal ingredients. The examination of the abdomen was negative. An exploring needle was inserted over the right base behind in three places, but with negative results.

During the next few days therc was nothing to report, except

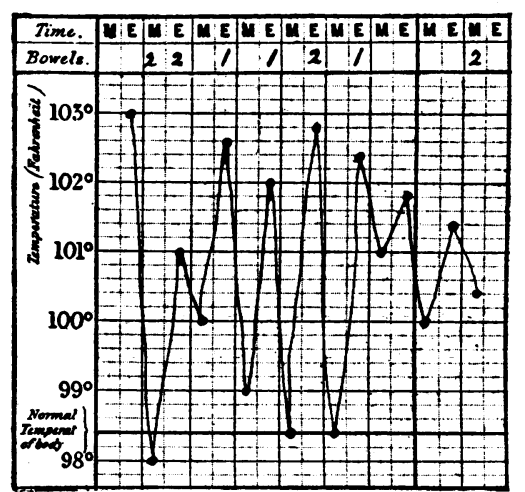

that he seen weakerand romited once, on September 25 th No tubercle bacilli were found in the sputum.

Phthisis seemed excluded, as there were no tubercle bacilli in the sputum, which was very free and purulent, and an ordinary empyema was negatived, as vibrations, though diminished, were still present at the right base, and an exploring syringe drew nothing. M y opinion was that he had an abscess of the lung or a localized enipyema between the lobes.

As he was getting worse and a fatal termination seemed certain, a needle was again inserted in two places over the right base, but drew no pus. I asked my surgical colleague to excise one or two ribs, and attempt to evacuate the abscess. One inch of the ninth rib was accordingly excised. The lung was found solid, and there was a little pus in the right pleura. The patient unfortunately collapsed, and died on the table.

At the post-mortem examination the lower lobe of the right lung was consolidated, and on section presented the appearance of grey hepatization with multiple small abscess cavities of grey hepatization with multiple small abscess cavitie scattered throughout-they were none of them larger than a large pea. As the appearance suggested actinomycosis, I had sections prepared which showed numerous small abscess cavities surrounded by dense leucocytic infiltration and were masses of Gram-staining streptothrix having the character were masses of Gram
of the ray fungus.

Actinomycosis affected the lung in about 15 per cent. of the recorded cases, but it is quite possible it is a much more common disease than is generally believed, a certain number being looked upon as non-tuberculous phthisis.

In the Journal of the American Medical Association for November 4th, 1911, Dr. Bridge of Los Angeles gives details of 17 cases. In some of these there was a mixed infection, tubercle bacilli being found in the sputum, and in most of them the sputum was noted as being very fetid.

Unless the little grains of actinomyces be found in the expectoration-they have a dirty grey and yellowish appearance, looking very like the roe of the herring-or

* Read at the meeting of the East York Division. 
the growth invades the chest wall and appears in the skin as a nodular irregular mass which breaks down, I think the diagnosis must be very difficult, but it is worth thinking of when the sputum is purulent and there are no tubercle bacilli, whilst there is no evidence of an empyema.

\section{fftemoratto:}

\section{MEDICAL, SURGICAL, OBSTETRICAL.}

\section{THE VALLE OF ANCHORED DRESSINGS IN} SURGERY.

I AM much interested in Mr. Lynn Thomas's article in the issue of the British Medical Journal of February 3rd, under the above heading, in which he describes as a new feature a roll of gauze fixed to a wount by deep sutmres.

I have been in the habit of using an exactly similar dressing to that he describes in nearly all my operation cases for more than six years. It firs; occurred to me to make use of a dressing fixed to the wound by sutures in cases in which there was difficulty in maintaining the ordinary dressings by means of bandages in accurate apposition to the wound, especially aftar operations in the submaxillary or cervical areas. By including a thick roll of gauze in a few deep sutures of salmon-gut, I found that I was able to keep my incisions accurately covered and that the dressings applied outside it did not tend to become displaced. Following this, I made use of the dressing in abdominal cases, when I found that there was no tendency for the external dressings or bandage to slip up upon the abdomen. From that time I have used it almost invariably after all abdominal operations, for inguinal and lumbar incisions, after cervical, and frequently after breast operations. In actual practice I use a firm roll of sterilized gauze about three inches longer than the incision it is desired to cover, passing my sutures through the skin and superficial fascia, and where possible picking up in the depth of the wound some of the deeper layers, the sutures at each end of the wound being placed a short distance from the actual end of the incision. The cutaneous margins are then sewn up with a continnous thread suture, covered by the roll of gauze and the salmon-gut sutures tied over it.

In many cases I made use of no other dressing for the wound outside this, but I found, especially in abdominal cases, that patients preferred the support and the feeling of reliance given by a firm bandage, ss that now I cover the gauze with wool and bandage it on. This form of dressing is particularly useful in cases in which there is much adipose tissue, as it almost entirely prevents any oozing taking place between the superficial planes of the wound. If it is desirable, as in renal operations, to make use of a drainage tube, I bring the latter through an opening in the gauze, taking care to place a suture over the latter on each side of the tube.

The dressing is certainly most comfortable to the patient, who does not feel any drag upon the wound on any movement; there is no fear of the wound becoming uncovered by slipping of the bandage, and usually, when it is re. mroved on the sixth or seventh day, it is hardly soiled, and not adherent to the incision. My successive liousesurgeons in charge of my cases hove been unanimously in favour of it

I do not claim any priority of discovery of this form of dressing; probably it was used by others before 1 thought of it some six years ago, in the same way that it has recently occurred to Mr. Lynn Thomas.

Loidon, W. R. H. Jocelyx Swan, M.S., F.R.C.S

\section{THE INTRAMUSCLLAR INJECTION OF} SALVARSAN.

IN September, 1911, a young gentleman, aged 28 years, came into my surgery armed with a note from a wellknown consulting surgeon, a fvising that the bearer should be salivated forthwith, with the object of diagnosing between cancer or syphilis. The patient had been for some time suffering from ax ulcerated tongue, with a pro. fuse and foul-smelling dis sharge, and as he thought his local medical man's treatment was not benefiting him $h_{c}$ consulted a specialist and brought his letter to me. I did not quite like the idea of salivation, ans from his history and a certain hesitation in his manner when answering my question, I believed him to be the victim of syphilis, and I suggested the intramuscular injection of salvarsan, and with his consent, and also the fult consent of his father, I injected the salvarsan into both glutei. 'He bore it well, had not a bad symptom, and his temperature never went higher than $100^{\circ}$. In less than a week after injection all discharge had ceased, and the bad taste had also gone (he used a liberal quantity of formamint). The tongue then commenced to heal rapidly, and on the nineteenth day after the injection it was perfectly healed, and had completely regained its normal condition, and my.patient since then has enjoyed most excellent health.

I think this case is very markedly in favour of the intra. muscular injection of salvarsan in syphilis, and I cannot help thinking that the danger is more in the intravenous injection than in the intramuscular, but we shall know more by-and-by, when we are able to watch whether the benefits received will be permanent. I have injected a gentleman suffering from advanced locomotor ataxia; although not by any means cured, he is well satisfied, and says he has been greatly benefited by the injection. Eccles.

ANDREW SPEARING.

\section{Reparty}

on

\section{MEDICAL AND SURGICAL PRACTICE IN THB HOSPITALS AND ASYLUMS OF THE} BRITISH EMPIRE.

\section{MACCLESFIELD INFIRMARY.}

A CASE OF APPENDIX ABSCESS IN AN UMBILICAL HERNIA. (By C. Averill, M.D., B.S.Durh., Honorary Surgeon to the Institution.)

THE patient in the following case, an adult and married woman, was admitted to the infirmary on July 3rd, with a history to the effect that on June 30th pain had commenced in an umbilical hernia of which she was the subject, coming on in spasms and lasting about an hour. On the following day she had vomited everything she took, and this had continued until admission; meantime the bowels had not been moved.

State on Admission. - The patient appeared very ill, her face very cyanosed, pulse 124 , temperature $99.8^{\circ}$, and respirations 28 The hernia, measuring about six inches in diameter, was red and intlamed, with patches of ulceration on the skin. A hard and intamed, with patches of ulceration on the skin. A hard impulse on coughing. The abdomen moved with respiration, impulse on coughing. The abdomen

Operation.-An operation was performed the same day. A vertical incision having been made over the sac to the left of the umbilicus, the former was opened, and it was found to contain gut and omentum adherent to the sac wall. On separating the adhesions a second sac was found to the right; this contained small intestine, the caecum, and the appendix, all verv inflamed and matted together. On separating these adhesions an abscess containing about four drachms of foul-smelling pus was found, situated at the neck of the sac just outside the abdominal cavity, the walls being formed partly of sac and partly of intestine. The pus was carefully mopped up with dry gauze and the abscess cavity wiped out with solution of hydrarg. biniodid. The appendix and some of the redundant omentum were remore omentum were remored, the adhesions re turned to the abdomen; a rubper drainage tube was then inserted, extending down to the pelvis, and the wound closed. An injection of pituitary extract was given at the end of the
operation. Rectal salines were ordered every two hours, and an injection of eserin gr. $\mathbf{1 0}$ overy eight hours.

Result.-The patient improved up to July 8th, when there was a rise of temperature and pulse-rate. On the 10th there was considerable discharge of pus from the upper part of the wound above the tube. She again improved until the 16th, when there was another rise of temperature. On the 19th, an area of rełmess was seen on the left side of the wound, from which a considerable amount of pus was evacuated. From this time onwards convalescence continued without further signs of pocketing and in a few weeks the patient was discharged quite well. 